\title{
The Whole "PROOF": Incorporating Evidence-Based Medicine Into Clinical Teaching
}

Nicholas M. Potisek, MD, ${ }^{\text {a }}$ Kenya McNeal-Trice, MD, ${ }^{\text {b }}$ Michael A. Barone, MD, MPHc

As part of the ongoing Council on Medical Student Education in Pediatrics series on skills used by great clinical teachers, this article introduces teaching strategies to more effectively convey the principles of evidence-based medicine (EBM), including a mnemonic that can serve as a framework for clinician educators.

EBM is the selective use of best current evidence to make medical decisions for individual patients. ${ }^{1}$ Incorporating medical evidence into clinical practice is an expectation for medical students entering residency. ${ }^{2}$ Routinely practicing EBM can promote patient safety, improve quality, and enhance value in health care. ${ }^{3}$ Resources exist for faculty to review the basic tenets of EBM. ${ }^{4}$

To ensure students entering residency have a strong foundation in EBM, clinical teachers need to teach EBM while providing patient care. Many interventions developed to improve teaching of critical appraisal skills are applicable to the classroom but not at the patient's bedside. 5,6 Clinician educators need to know how to guide trainees through the process of establishing answerable clinical questions, appraising evidence, and applying evidence to patient care.

Clinical educators are faced with several challenges to teaching EBM, such as lack of time and a paucity of EBM curriculum requirements. ${ }^{7}$ Learning EBM is difficult because students may lack clinical role models, wrestle with acknowledging uncertainty, and struggle with applying evidence to patient care. ${ }^{8}$ If barriers are not addressed, an inability to incorporate EBM into patient care can persist into residency training and beyond. ${ }^{9}$

The key elements of EBM can be summarized by using the mnemonic PROOF (Table 1): Propose a clinical question, review the literature, organize and appraise literature search results, overlap evidence and specific patient care needs and values, and follow patient outcomes. The following clinical scenario helps illustrate how to use PROOF in a clinical teaching setting.

A 6-year-old girl with mild persistent asthma presents for a follow-up visit 3 days after treatment in an emergency department (ED). Review of the ED visit reveals that $\beta$-agonists and a single dose of dexamethasone led to the patient's clinical improvement and her discharge from the ED. Today, before entering the clinic room to see the patient, your medical student asks, "Can a single dose of dexamethasone be used to reduce hospitalization? I've primarily seen a 5-day course of prednisone used."
aDepartment of Pediatrics, Wake Forest Baptist Medical Center, Winston-Salem, North Carolina; 'D Division of General Pediatrics and Adolescent Medicine, North Carolina Children's Hospital, Chapel Hill, North Carolina; and ${ }^{C}$ Department of Pediatrics, Johns Hopkins University School of Medicine, Baltimore, Maryland

Drs Potisek and Barone conceptualized, designed, and drafted the initial manuscript; Dr McNeal-Trice drafted the initial manuscript; and all authors revised the manuscript and approved the final manuscript as submitted.

Dol: https://doi.org/10.1542/peds.2017-1073

Accepted for publication Mar 29, 2017

Address correspondence to Nicholas M. Potisek, MD, Department of Pediatrics, Wake Forest School of Medicine, Medical Center Blvd, Winston-Salem, NC 27157. E-mail: npotisek@wakehealth.edu

PEDIATRICS (ISSN Numbers: Print, 0031-4005; Online, 10984275).

FINANCIAL DISCLOSURE: The authors have indicated they have no financial relationships relevant to this article to disclose.

FUNDING: No external funding.

POTENTIAL CONFLICT OF INTEREST: The authors have indicated they have no potential conflicts of interest to disclose.

To cite: Potisek NM, McNeal-Trice K, Barone MA. The Whole "PROOF": Incorporating Evidence-Based Medicine Into Clinical Teaching. Pediatrics. 2017;140(1):e20171073 
TABLE 1 PRO0F Strategies

Propose a clinical question

Review the literature

Organize and appraise search results

Overlap evidence and specific patient care needs and values

Follow patient outcomes
Key EBM Elements

\section{Clinical Strategies}

Guide PICO-formatted questions

What is the question we are trying to answer? Can this question be framed into PICO format?

If you designed a study to answer this question, what patient population would you study?

Any specific inclusion or exclusion criteria to consider?

Select topics for learners with sufficient evidence to explore

Identify specific systematic reviews, guidelines, or research articles for learners

Review references from articles, reviews Introduce Cochrane database or BMJ Clinical Evidence

Have team member demonstrate search strategy

Incorporate medical librarians and informationists

Ensure leaners know hierarchy of evidence

Have learners focus on specific aspects of critical appraisal (internal and external validity, number needed to treat, likelihood ratios)

Guide questions to ensure care is patient specific Is this patient similar to those included in the study? Do our treatment options meet our patient's values? Use JAMA series “Users' Guides to the Medical Literature" Debrief patient outcomes

Emphasize use of medical literature in decision making during patient encounters

Role model and acknowledge challenges by using EBM in various clinical situations

\section{PROPOSE A CLINICAL QUESTION}

Formulating a clinical question is essential to the practice of EBM. Clinical educators can model how to develop clinical questions during routine delivery of patient care. Learners can be guided through intentional questions to characterize the patient population, intervention, comparison, and desired outcome (PICO), ${ }^{10}$ such as "What is the clinical question we are trying to answer for this patient?" or "If you were designing a study to answer this clinical question, what patients would you want to include?" Instead of referencing a specific article, learners can benefit when a clinical educator helps facilitate question framing by selecting topics with sufficient evidence available to explore. Clinical questions structured in the PICO format can improve search results. ${ }^{11}$ In our example, the question posed by the student can be framed into the following PICOstyle clinical question: "Are children with an acute asthma exacerbation [patient population] who receive dexamethasone [intervention] instead of 5 days of prednisone [comparison] less likely to be admitted to the hospital [outcome]?"

\section{REVIEW THE LITERATURE}

Clinical educators can guide learners to specific, relevant systematic reviews, guidelines, or research articles. References from these evidence summaries can be used to identify appropriate articles. Learners can be pointed to the Cochrane Database of Systematic Reviews or BMJ Clinical Evidence to jump-start their searches. ${ }^{12,13}$ When conducting evidence searches, the learner can demonstrate his or her search strategy to the team. Clinical educators can then demonstrate their own search strategies and compare them to the learner's strategies and results. Incorporating the expertise of medical librarians and informationists can promote interprofessional collaboration and assist when clinical demands limit time to perform searching. Informationists are clinical librarians with specific training in information-seeking skills and knowledge in a given specialty area. Literature searches can be made more efficient by using appropriate filters and/or limits, display settings, full-text icons, clinical queries, medical subject headings, and related citations. In our example, the clinical educator could specifically ask the student to find a recent 2014 systematic review published in Pediatrics to help start the search and then view related citations. ${ }^{14}$

\section{ORGANIZE AND APPRAISE LITERATURE SEARCH RESULTS}

Appraisal of the literature remains a challenge to teach while providing clinical care because of time constraints. An initial first step is ensuring students learn the hierarchy of evidence. Randomized controlled trials represent the highest quality evidence, followed by observational studies, case reports, and finally, expert opinion. Structured formats to appraise articles should be made available to learners. Among the most well-known is The Journal of the American Medical Association (JAMA) series entitled 'Users' Guides to the Medical Literature."15,16 Great clinical educators encourage a structured critical analysis of the literature, and these resources provide students with a logical framework. When teaching critical appraisal techniques, it is essential not to overload the learners. For example, if a learner is reviewing an article for the team, have him or her focus on 1 aspect of critical appraisal. In our example, the student could be asked to review how to interpret the forest plots included in the systematic review.

\section{OVERLAP EVIDENCE AND SPECIFIC PATIENT CARE NEEDS AND VALUES}

Emphasizing the importance of using evidence to meet specific patient needs is a critical step in the successful implementation of clinical EBM. The question "Is this 
patient similar to those included in the study?" can demonstrate the application of evidence to a specific patient. It is often useful to point out the limitations of studies generalized to a specific patient's care, highlight the ambiguity of medicine, and have learners observe your discussion with the patient and the patient's family about such ambiguity. Resources to help match evidence with specific patient care needs and values include the JAMA series and a manual for evidence-based clinical practice. ${ }^{15,17}$ In our example, the clinical educator could ask the student to assess either the severity of asthma among patients included in the systematic review or the dose of dexamethasone provided.

\section{FOLLOW PATIENT OUTCOMES}

Finally, following a patient's response to an EBM-guided test or treatment validates the relevance of EBM for learners. Intentionally debriefing patient outcomes of EBM decisions allows each learner to explore context and generalizability to future clinical practice. When communicating with patients and families, clinical educators should model the emphasis on how the medical literature was used to guide diagnostic or treatment decisions. In our example, one could encourage the student to call the patient's caretakers a few days after the EBM-guided decision to assess continued recovery or any additional unscheduled care. Skilled clinicians acknowledge the difficulty of balancing available evidence, anecdotal experiences, and individual patient preferences when making clinical decisions. Transparency in a clinician's thought process helps learners refine their clinical decision-making and creates a safe environment to discuss appropriate use of EBM.

\section{CONCLUSIONS}

Great educators understand that teaching clinical skills such as diagnostic reasoning and performing physical examinations can be enhanced through the use of frameworks. The same is true for EBM. PROOF can assist all team members in learning the necessary steps for proposing and answering clinical questions through use of the medical literature. Learners want PROOF that evidence-based care can benefit patients.

\section{ABBREVIATIONS}

EBM: evidence-based medicine

ED: emergency department

JAMA: The Journal of the American Medical Association

PICO: patient, intervention, comparison, and outcome

PROOF: propose, review, organize, overlap, and follow

\section{REFERENCES}

1. Sackett DL, Rosenberg WM, Gray JA, Haynes RB, Richardson WS. Evidence based medicine: what it is and what it isn't. BMJ. 1996;312 (7023):71-72

2. Association of American Medical Colleges. Core entrustable professional activities for entering residency (updated). Available at: www. mededportal.org/icollaborative/ resource/887. Accessed March 20, 2016

3. Medicine IoMRoE-B. Institute of Medicine: Roundtable on EvidenceBased Medicine. Washington, DC: National Academy of Sciences; 2009

4. Isenburg MV. LibGuides: evidencebased practice. http://guides. mclibrary.duke.edu/ebm. Accessed 0ctober 26, 2016

5. Maggio LA, Tannery NH, Chen HC, ten Cate 0, 0’Brien B. Evidence-based medicine training in undergraduate medical education: a review and critique of the literature published 2006-2011. Acad Med. 2013;88(7):1022-1028

6. Tilson JK, Kaplan SL, Harris JL, et al. Sicily statement on classification and development of evidence-based practice learning assessment tools. BMC Med Educ. 2011;11:78

7. Oude Rengerink K, Thangaratinam S, Barnfield G, et al. How can we teach
EBM in clinical practice? An analysis of barriers to implementation of on-thejob EBM teaching and learning. Med Teach. 2011;33(3):e125-e130

8. Maggio LA, ten Cate 0 , Chen $\mathrm{HC}$, Irby DM, O'Brien BC. Challenges to learning evidence-based medicine and educational approaches to meet these challenges: a qualitative study of selected EBM curricula in U.S. and Canadian Medical Schools. Acad Med. 2016;91(1):101-106

9. Green ML, Ruff TR. Why do residents fail to answer their clinical questions? A qualitative study of barriers to practicing evidence-based medicine. Acad Med. 2005;80(2):176-182

10. Richardson WS, Wilson MC, Nishikawa J, Hayward RS. The wellbuilt clinical question: a key to evidence-based decisions. ACP J Club. 1995;123(3):A12-A13

11. Schardt C, Adams MB, Owens T, Keitz S, Fontelo P. Utilization of the PICO framework to improve searching PubMed for clinical questions. BMC Med Inform Decis Mak. 2007;7:16

12. Cochrane, John Wiley \& Sons. Cochrane Library. Available at: www. cochranelibrary.com/. Accessed 2016

13. BMJ Publishing Group. Welcome to BMJ Clinical Evidence. Available at: http://clinicalevidence.bmj.com/x/ index.html. Accessed October 26, 2016

14. Keeney GE, Gray MP, Morrison AK, et al. Dexamethasone for acute asthma exacerbations in children: a metaanalysis. Pediatrics. 2014;133(3):493-499

15. Guyatt GH, Sackett DL, Cook DJ. Users' guides to the medical literature. II. How to use an article about therapy or prevention. A. Are the results of the study valid? Evidence-Based Medicine Working Group. JAMA. 1993;270(21):2598-2601

16. Jaeschke R, Guyatt G, Sackett DL. Users' guides to the medical literature. III. How to use an article about a diagnostic test. A. Are the results of the study valid? Evidence-Based Medicine Working Group. JAMA. 1994;271(5):389-391

17. Guyatt G, Rennie D, Meade M, Cook D; American Medical Association. Users' Guides to the Medical Literature. A Manual for Evidence-Based Clinical Practice. 3rd ed. New York, NY: McGraw-Hill Education Medical; 2015 